\title{
L2 Motivational Self System Among Arab EFL Learners: Saudi Prespective
}

\author{
Ali Ayed S. Alshahrani \\ University of Bisha, Saudi Arabia \\ E-mail: alalshhrani@ub.edu.sa
}

Received: 15-04-2016

Accepted: 17-06-2016

Published: 01-09-2016 doi:10.7575/aiac.ijalel.v.5n.5p.145

Advance Access Published: July 2016

URL: http://dx.doi.org/10.7575/aiac.ijalel.v.5n.5p.145

\begin{abstract}
The current paper investigates the validity of the motivational L2 self system tripartite model as to explaining the L2 motivational behaviours of a sample of Arab university level EFL students in southern Saudi Arabia. Dörnyei's L2 Motivational Self System (2009) is used as the theoretical framework. A survey was designed and administered to about 400 Saudi male undergraduate students majoring in English. The obtained data were coded and analysed. The results upheld the validity of the of the L2 Self System model's core components of Ideal L2, Ought-to L2 and learning experiences of English, as well as their relevance in the Saudi context. The findings indicated high significance levels and strong contributions from the Ideal L2 and Language Learning Experiences to the learners' reported efforts in learning English as the criterion measure. Both components make stronger contributions to explaining the variance than Ought-to L2 component.
\end{abstract}

Keywords: Motivational self-system, Arab learners, EFL context

\section{Background}

Language shapes actions (Dörnyei, 2005; 2007). Indeed, the factors that motivate learners to acquire a second language and shape the direction and magnitude of learners' action, constitute integrative orientation. Integrativeness represents learners' desires and aspirations to be identified as members of the L2 linguistics community and be able to mix with the target language speakers' community (Gardner, 1985). The integrative orientation acts as the fundamental component of the socio-psychological theory proposed by the pivotal research work of Robert Gardener and his associate (Gardner \& Lambert, 1972) which assumed that "most of the attitudinal, cognitive-situational, and motivational variables believed to predict success or failure in second language learning" (Gardner, 1985). The integrative concept has strongly overshadowed L2 motivation research literature for many generations, and has given rise to numerous insights into L2 motivation.

The swift development of telecommunication and the process of globalisation have deterritorialised the attitudes and attribution of beliefs about language as a sole trait fits to a single locale (Blommaert, 2010). Learners' perceptions of English as a global language (lingua franca) have highlighted the integrative concept's failure to uphold the multiversity of the new conceptualisations of the multidimensional social identity construct prevalent in multilingual and multicultural societies (Coetzee-Van Rooy, 2006; McNamara, 1997; Norton, 1995). This complexity is a prime drawback and a strong criticism of Gardner's theory of L2 motivation. Indeed, many researchers have admitted that the latter is inappropriate for different educational and cultural situations outside Canada (Crooks \& Schmidt, 1991), that it fails to integrate with recent cognitive-situated theories of motivation (Oxford \& Shearin, 1994), and that it is incapable in today's globalisation era (e.g., Lamb, 2004; McClelland, 2000). These developments have fuelled debate surrounding a possible, and substantial, reconceptualisation of motivational theory to language learning, in a way that builds on prior understanding of L2 motivation and "[it] is embedded and develops within a complex web of environmental and social influences" (Fan, 2011, p. 159). Indeed, this conceptualisation would be valid to global English in the 21 st century and would place great emphasis on how learners' image of themselves as language learners effects their learning progress (Dörnyei, 2005; 2009).

In order to accommodate previous research findings, a new motivational paradigm is presented by Dörnyei (2005). He proposed a conceptual framework that presents motivation as the result of learner's aspiration to diminish the discrepancy between his/her image of what he/she would like to become, and his/her actual self-state. The L2 Motivational Self System paradigm presents an assemble of two recent conceptualisations of motivation put forth by Noels (2003) and Ushioda (2001); this can also be said of research into personality psychology on possible selves and identity by Higgins (1987) and Markus \& Nurius (1986), as well as Dornier's empirical research (2005, 2009).

\subsection{The L2 Motivational Self System}

Dörnyei debated that the L2 Motivation Self System concept of self-perspective is synchronised with the integrative concept of previous L2 motivation traditional theories to present a holistic reference. Indeed, this reference helps to 
explain the motivational features in diverse learning contexts where there is limited contact with L2 speakers. The L2 Motivation Self System is well suited to investigating the motivational traits of language Franca in this age of globalisation.

Dörnyei $(2005,2009)$ proposed that the L2 Motivational Self System model comprises of three main dimensions: The Ideal L2 self, the Ought to L2 self, and the L2 learning experience.

The Ideal L2 Self is the principal constituent and is centred around the internal desires of the learner. Dörnyei (2005) explained it as "the L2 specific facet of one's ideal self” (p. 106). It represents an ideal image of the kind of L2 user one desires to become in the future, namely a proficient orator of an L2. It acts as an influential motivate to diminish the variances between the learners' real self, and this imaginary ideal image. It also regulates positive outcomes, that is, one's aims and expectations of being successful in the L2 on personal and professional levels. The Ought-to L2 self is the L2-specific aspect of one's ought-to self. It is grounded around the motivational regulations shaped by the social pressure of affecting persons in the learners' surrounding environment such as including family, peers and language instructors. The Ought-to L2 Self refers to the traits that one should retain to meet anticipations and to evade undesired results. Moreover, this less-internalised aspect of the L2 self pertains these attributes to "perceived duties, obligations, or responsibilities" (Dörnyei, 2005, p.106). The last constituent of the model is the L2 learning experience. It is centred around the learners' "actual experience of being engaged in the learning process" (Dörnyei, 2009, p. 218). It acknowledges the impact of the immediate situation-specific motives (e.g. classroom processes, teachers, textbooks, assessment criteria and achieved grades) on learners' engagement in the learning process and experience.

The tripartite L2 Motivational Self System model has already been empirically scrutinised in a range of diverse EFL contexts, including Japan (Ryan, 2009; Sampson, 2012), China (Chen, Wardpen, \& Chang, 2005; You, Dörnyei, \& Csizér, 2015; Magid \& Chan, 2012; Huang, Hsu, \& Chen, 2015), Iran (Papi, 2010; Papi \& Teimouri, 2012), Hungary (Csizér \& Kormos, 2009), Chile (Kormos, Kormos, Kiddle \& Csizér, 2011), Saudi Arabia (Alshehri, 2009), Indonesia (Lamb, 2012),Pakistan (Islam, Lamb \& Chambers) and Korea (Kim \& Kim, 2014). Some of these countries have also been compared with each other in terms of their use of this model; an example would be Taguchi, Magid, \& Papi, (2009)'s comparative study of the Chinese, Japanese, and Iranian EFL contexts. These studies have mostly confirmed the multilateral construction of the model.

The Ideal L2 self-dimension has been found to be the strongest component of the model when it comes to predicating the variance in learners' intention to learn the language and their learning behaviours in EFL contexts. In contrast, Lamb (2012)'s study of Indonesian high school students' Ideal L2 selves, revealed suppressing results. Lamb attributed this to the ideal image and vague view of this component during the early adolescence period. The Ideal L2 selfdimension was found to positively correlate with integrativeness and instrumental motives (Taguchi et al., 2009). It was also found to be effected by students' future self-image progress during their language learning period (Papi, 2010).

These recent empirical investigations revealed the weak contribution of the Ought-to L2 self dimension in shaping the learning behaviours of EFL/ESL learners. The Ought-to L2 self has a limited capability when it comes to predicating the variance in learners' behaviour while they are studying the language (Csizér \& Kormos, 2009; Kormos et al., 2011; Papi, 2010; Taguchi et al., 2009). It was considerably less effective in predicting the variance in learners' language learning behaviours when compared to the Ideal L2 self dimension. However, the Ought-to L2 self-correlated more closely with the prevention-focussed aspects of instrumentality motives, as well as the influence of family members, close friends and school authority personnel, specifically in Arab and Asian cultures (Alshahri, 2009; Islam et al., 2013; Taguchi et al., 2009; Papi, 2010).

The L2 learning experience dimension of the L2 Motivational Self model has a similar effect in shaping learners' learning attitudes and motivated behaviours. It has proven to have the same effect on the criterion measures as the Ideal self dimension within specific regional contexts. The L2 learning experience concerns learners' attitudes toward second language learning and can be affected by situation-specific motives related to the immediate learning environment and experience. For instance, learning experiences have been found to strongly predict learning behaviours in most EFL students reviewed studies. However, some studies have found this dimension to be less effective in the Chinese students' situation. Indeed, this was the case in a study by Taguchi et al., (2009) as well as Lamb (2012)'s analysis of Indonesian students.

The objectives of the current study were two-fold, and involved the empirical investigation of: Firstly, the validity of the L2 Motivational Self system tripartite model as a means of explaining the L2 motivation of a sample of Arab university level EFL students in southern Saudi Arabia in an actual EFL context (compared to Alshehri's 2009 study mixed Saudi EFL ESL sample). Indeed, this study looked at students' English background which play a paramount role in shaping and sustaining students' L2 learning motivation. Secondly, the validity of equating the ideal L2 self with integrativeness. With these objectives in mind, the following research questions were formulated:

1. Can the Ideal L2 self be equated with integrativeness in the Saudi EFL context?

2. What is the relationship between the three main components of the L2 Motivational Self system and with learners' reported efforts to learn English?

3. Which other motivational factors appear to be essential in predicting and explaining variance in L2 motivational behaviour in the Saudi EFL context? 


\section{Method}

\subsection{Study sampling}

The study sample targeted students majoring in English at a southern Saudi Arabian university campus during the 2015 fall semester. All students in their second, third and fourth year were asked to fill in the online questionnaires so as there was a broadly representative sample. The students were informed that their decision to participate would in no way affect their grades and that their participation in the study was strictly voluntary. More than 400 male students answered the questionnaire. The participants were young adults aged between 17 and 24 from various socio-economic backgrounds with an intermediate proficiency level. All the participants had studied English as a foreign language in public school for 6 years and then as a major for a period ranging between 2 and 5 years. 397 complete questionnaires were included in the data coding and analysis process, while incomplete questionnaires or those in which the same answer had been chosen for every question, were excluded ( 24 in total).

\subsection{Instrument}

The study assessed the latent variables in the model by using several six-point Likert type items adapted from recent L2 motivation self-system studies by Dörnyei (2005), Kormos \& Csizér, (2005), Dörnyei et al. (2006), Taguchi et al. (2009), Ryan (2009) and Papi (2010). These latent dimensions proved to be important predictor variables of motivated learning behaviour and played a key role in explaining the different language-related self-future image. The final questionnaire comprised six-point Likert type items ranging across 10 motivational scales that could be completed in approximately 30 minutes. For most of the statements, respondents had to indicate their agreement on a six-point Likert scale ranging from 1 (strongly disagree) to 6 (strongly agree); in order to provide variety, there were also some yes/no questions answered on a scale ranging from 1 (not at all) to 6 (very much). The 10 motivational variables were:

(1) Criterion measure: assesses the learners' intended efforts toward learning English. For example: I am working hard at learning English.

(2) Ideal L2 self: attributes to L2-specific facet of one's ideal self-image. For example: I can imagine myself living abroad and having a discussion in English.

(3) Ought-to L2 self: measures 'the attributes that one believes one Ought-to possess (i.e. various duties, obligations, or responsibilities) in order to avoid possible negative outcomes'. For example: I study English because close friends of mine think it is important.

(4) Family influence: examines parental encouragement toward learning the language: For example: $M y$ parents encourage me to take every opportunity to use my English.

(5) Instrumentality-promotion: measures the regulation of personal encouragements to becoming successful. For example: Studying English is important to me

because English proficiency is necessary for promotion in the future.

(6) Instrumentality-prevention: measures the regulation of duties and obligations such as studying English in order to pass an examination. For example: Studying English is necessary for me because I don't want to get a poor score or a fail mark in English proficiency tests.

(7) Attitudes to learning English: measures situation-specific motives

related to the immediate learning environment and experience. For example: I really enjoy learning English.

(8) Attitudes to L2 community: investigates learners' attitudes toward members of the target language community. For example: Would you like to know more about people from English-speaking countries?

(9) Cultural interest: measures learners' interest in the target language's cultural products, such as TV, magazines, music and movies. For example: Do you like English films?

(10) Integrativeness: entails having a positive attitude toward the second language, its culture, and the native speakers of that language. For example: How important do you think learning English is in order to learn more about the culture and art of its speakers?

\section{Procedures}

An initial draft of the questionnaire scales was prepared. This was then translated from English to Arabic before being back-translated by bilingual English-Arabic translation experts at the English department. Several problematic items were reworded, following which the questionnaire was piloted with 41 undergraduate students at the target university. The piloting stage data analysis of factors and reliability indicated problems related to the reliability of several scales, as well as problematic rewording items. Items with a low Cronbach alpha internal consistency coefficient $(\propto \leq 0.6)$ were removed and final rewording of a few items was performed. Before administering the questionnaire, it was essential to obtain permission from the university as well as consent from the students. Once this had been achieved, the coordinated teachers explained the purpose of the study. Students were told that their participation was voluntary and that their identity would remain anonymous, as they would be able to complete the electronic questionnaire in their free time, inside the university or at home. The obtained data were first computer-coded by using SPSS (version 21) for windows. The Cronbach Alpha internal consistency reliability coefficients were computed (Table 1). The results indicated that all of the scales had acceptable alpha values in line with the generally accepted standards of social 
science; that is, above 0.60 (Pallant, 2007). As the list of variables in Table 1 indicates, the cornerstones of Dronie's 2005 tripartite construct, namely Ideal L2 self, Ought-to L2, and Language learning experience, emerged as distinct latent dimensions with high reliability coefficients $(0.86,0.84$, and 0.81 respectively). Results also brought into focus learners' attitudes to L2 community and family influence, as well as learners' fears, duties and obligations in the future (instrumentality prevention) toward learning the foreign language; indeed, both were found to be important antecedents to learning behaviour $(0.86,0.83$ and 0.82 respectively). The remaining factors (listed in Table 1$)$ emerged with acceptable reliability coefficients (above 0.7 ) and thus were found to play major roles in predicting and explaining the L2 motivational model in the Saudi context.

Table 1. Composites of attitudinal/motivational variables with Cronbach Alpha coefficients

\begin{tabular}{lllll}
\hline Factor name & No. of items & $\propto$ & M & SD \\
\hline Intended learning efforts & 6 & 0.78 & 4.4 & 0.99 \\
Ideal L2 self & 6 & 0.86 & 4.5 & 1.09 \\
Ought-to L2 self & 6 & 0.84 & 4.2 & 1.15 \\
Family influence & 6 & 0.83 & 4.1 & 1.04 \\
Instrumentality promotion & 5 & 0.79 & 4.4 & 1.05 \\
Instrumentality prevention & 6 & 0.82 & 4.5 & 1.04 \\
English learning experiences & 6 & 0.81 & 4.4 & 1.05 \\
Cultural interest & 4 & 0.74 & 4 & 1.27 \\
Attitudes to L2 community & 4 & 0.86 & 4.6 & 1.35 \\
Integrativeness & 3 & 0.83 & 4.7 & 1.34 \\
\hline
\end{tabular}

The analysis of the motivational variables, means and standard deviation values for the whole sample revealed high mean values. This indicates that: a) the participating EFL students are highly motivated to learn English and b) there are multiple factors affecting their desire to learn that language. Among these scales, Ideal L2 self, attitudes toward L2 community members, Instrumentality (Prevention), and experiences of Learning English and Instrumentality (Promotion) had the highest mean values. Intended Learning Effort was also among the highest mean scores, which implies that this sample of Saudi students are willing to exert more effort in learning English.

\section{Results and Discussion}

\subsection{The relationship between Ideal L2 and integrativeness in the Saudi EFL context}

Table 2 shows a remarkably high correlation between the ideal L2 self and integrativeness in the Saudi EFL context. This correlation suggests that the two concepts tap into the same construct domain and are therefore equal. Table 2 indicates that the Ideal L2 self-achieved a better explanatory power of the variance in the key criterion measure of learners' intention to study than integrativeness. These findings support those of previous studies which investigated the capability of Ideal L2 to re-interpret integrativeness in a broader frame of reference.

Table 2.The relationship between the ideal L2 self and integrativeness

\begin{tabular}{ll}
\hline & Ideal L2 \\
\hline Integrativeness & 0.57 \\
\hline $\mathrm{P}<0.001$ &
\end{tabular}

\subsection{The relationship between the L2 Motivational Self system's three main components}

To explore the relationship between the model's three main components and to compare them with the other motivational factors investigated in the study correlation and regression tests were conducted. Pearson correlation analysis was performed to disclose the linear relationships existing between the model factors, and to identify the strength of these relations. The findings (Table 2) revealed that the Ideal L2 self has the strongest linear relation with the criterion measure (0.76) which is similar to the results from Pakistani and Japanese EFL learning contexts (Islam et al., 2013; Ryan, 2009) and greater than those found in Chinese and Iranian contexts (Papi, 2010; Taguchi et al., 2009). 
Results also revealed a strong relationship between the three components of the L2 Motivational Self System. Particularly, the correlation between Ideal L2 self and L2 English Learning Experiences (0.64) was stronger than the Ought-to L2 self's correlation with each of them (0.53 and 0.55$)$ respectively. The correlation between the English Learning Experiences and learners' L2 cultural interest and attitudes to L2 community members was quite high (0.62 and 0.64); indeed, this indicates the strong influence of learners' sense of emotional identification with the L2 community and their culture on their inclination to study English. The relation of the Ought-to L2 self with the criterion measure was weaker than that of Ideal L2 self and the English Learning Experiences $(0.5,0.76 \& 0.73)$ respectively, while its correlation with family influence was much stronger (0.75). Instrumentality (Promotion) had the highest correlation with Ideal L2 self (0.78). By contrast, Instrumentality (Prevention) had the highest correlation with Ought-to L2 self $(0.74)$. The correlation between the promotion and prevention dimensions of instrumentality was very low (0.35).

Table 3. Correlation of Motivational L2 Self system scales

\begin{tabular}{|c|c|c|c|c|c|c|c|c|c|c|}
\hline Scale & 1 & 2 & 3 & 4 & 5 & 6 & 7 & 8 & 9 & 10 \\
\hline 1. Intended Learning Efforts & - & & & & & & & & & \\
\hline 2. English Learning Experiences & .727 & - & & & & & & & & \\
\hline 3. Ideal L2 & .755 & .636 & - & & & & & & & \\
\hline 4. Ought to L2 & .502 & .529 & .547 & - & & & & & & \\
\hline 5. Cultural Interest & .474 & .622 & .513 & .412 & - & & & & & \\
\hline 6. Family Influence & .554 & .547 & .592 & .754 & .466 & - & & & & \\
\hline 7. L2 Community & .545 & .636 & .569 & .340 & .650 & .400 & - & & & \\
\hline 8. Integrativeness & .398 & .422 & .513 & .401 & .372 & .429 & .365 & - & & \\
\hline 9. Instrumentality Promotion & .512 & .625 & .736 & .530 & .483 & .670 & .570 & .627 & - & \\
\hline 10. Instrumentality Prevention & .463 & .460 & .577 & .783 & .426 & .686 & .497 & .564 & .349 & - \\
\hline
\end{tabular}

In order to establish which motivational factors act as the best predictor variables when it comes to Saudi EFL learners' motivated learning behaviour, multiple regression analysis with Stepwise was conducted. The aim of this was to ascertain which motivational scales contributed most to the L2 motivation of the participants by predicting their reported learning efforts. Test assumptions of multicollinearity, linearity and normality were verified and the results indicated that none of these assumptions were violated.

Table 4. Results of the regression analysis of the motivational scales with learning effort and behaviour as the criterion variable for Saudi EFL learners

\section{Final model}

\begin{tabular}{llll} 
Variable & $B$ & $S E B$ & $\beta$ \\
\hline Learning experience & & & $.41^{*}$ \\
Ideal L2 self & .40 & .043 & $.39^{*}$ \\
Instrumentality-prevention & .39 & .044 & $.17^{* *}$ \\
Cultural Interest & .20 & .04 & $.09 * * *$ \\
\hline Ought-to L2 & .07 & .034 & .015 \\
$R^{2}$ & .012 & .042 & .70 \\
$F$ for change in $R^{2}$ & & & $4.4^{* * *}$ \\
\hline$* p<.001$ & & & \\
$* * \quad p<.01$ & & & \\
$* * * \quad p<.05$ & & &
\end{tabular}

Table 4 depicts a model of the four scales, namely English Language Learning experience, Ideal L2 self, Instrumentality-prevention, and Cultural Interest; indeed, this model shows which are the best predictors of the reported learning effort variable. The model has a multiple correlation coefficient $(\mathrm{R})$ value of 0.7 , which indicates that approximately $70 \%$ of the variance in the students' reported learning effort variable may be explained by the model. 
Indeed, according to the standards of research in L2 motivation reported by Dörnyei, (2009, p. 31) this may be considered a highly respectable value.

The study's findings present further support for the integrity of Dörnyei's L2 self-related motivational model, which is used to assess variances in L2 learners' motivational behaviours in this era of technological revolution. The L2 Motivational Self system's core components of Ideal 12, Ought-to L2 and Language learning experiences (presented in Table 3), were among the four scales which contributed significantly to Saudi EFL learners' English language reported learning effort. The findings indicate high significance levels $(p<.001)$ and strong contributions from the Ideal L2 and Language learning experiences to the learners' reported efforts in learning English as the criterion measure. Both components strongly contribute to explaining the variance in the learners' motivational behaviours (41\% and 39\%) respectively. However, the contribution of Language learning experiences is slightly higher than that of Ideal L2 when it comes to learners' reported learning efforts. These findings reveal the impact of the Ideal L2 self as well as the significant impact of learning experience on students' motivated learning behaviour in the Saudi EFL context; indeed, the results mirror those from the literature on L2 self system studies in other Asian contexts.

The Ought-to L2 self dimension influence was in contrast with the other two decisions of the L2 motivational self model. The Ought-to L2 self had a marginal effect as it makes a weak contribution to predicating students' learning motivational behaviour (explaining only $0.2 \%$ of the variance in the reported Learning Efforts). This result was in agreement with similar findings reported in five different Asian EFL contexts: Japan, China, Iran (Taguchi et al., 2009), Indonesia (Lamb, 2012), and Pakistan (Islam et al., 2013). Indeed, this also underlines the stronger impact of Ought-to L2 self over that of Ideal L2 self and learning experience dimensions when it comes to shaping L2 learners' motivational learning behaviours.

The results also indicated a highly significant correlation $(0.75)$ and strong contribution from family encouragement and learners' duties and obligations (instrumentally preventions) factors on their Ought-to L2 selves (Table 5). This mirrors the significant role of family, peers, and friends in the shaping of learners' futures. This relationship was affirmed by related studies conducted by Taguchi et al. (2009) in Japan, China, and Iran, in Hungary by Csizér \& Kormos (2009) and in Chile by Kormos et al. (2011). However, the link between the Ought-to L2 self and parental encouragement in the Saudi context is considerably stronger than in the other Asian countries investigated in the above-mentioned studies. This may be related to how learners, as well as their families and friends view language learners as language users; it may also be linked to their highly exam-oriented foreign language system, which may be similar to that used in Japan, China, Pakistan and Iran.

Table 5.Results of the regression analysis of the motivational scales with the Ought-to L2 self as the criterion variable for Saudi EFL learners

\section{Final model}

\begin{tabular}{llcl} 
Variable & $B$ & $S E B$ & $\beta$ \\
\hline Family Influence & .813 & .055 & $.663 *$ \\
Instrumentality Prevention & .189 & .051 & $.165^{*}$ \\
$R^{2}$ & 0 & & .58 \\
$*_{p}^{*}<.001$ & & &
\end{tabular}

The findings also showed a significant correlation between Ideal and Ought-to selves (0.57), which is a vital condition for maximising their 'motivational impact' and inducing learners to make desired efforts to achieve their goals (Dörnyei, 2009). Indeed, this was also in line with Oyserman et al. (2006)'s argument that Ideal L2 and Ought-to future selves are not necessarily in opposition to each other. Moreover, the findings revealed a substantial correlation between the promotional aspect of instrumentality and the Ought-to L2 self among Saudi learners of English (0.53). These findings were expected, as learners might not yet have developed a self-internalised image of what they really want to become. Indeed, this is entirely discrete from what they ought to be as an impact of the collective nature of interpersonal relationships in Saudi society, where learners view themselves as more interdependent than other members of society. (Heyn, 2013).

\subsection{Other motivational variables predicting variance in Saudi EFL learners' learning behaviour}

In addition to the main components of the L2 Motivational Self system, Table 3 indicates that two scales of the model make a significant contribution to the prediction of the study sample's reported learning efforts: Cultural Interest, and the prevention-focussed aspects of instrumentality. Cultural Interest uniquely explained $4.5 \%$ of variance in the dependent variable. The findings indicated that a cultural interest toward products coming from English speaking communities contributes significantly to positively motivating Saudi EFL learners' learning efforts. It is also an indication that learners' general open-mindedness about various cultures around the world will enhance their willingness to learn foreign languages (Gardner, 2006). In fact, this finding confirms those from previous studies, which 
concluded that cultural interest emerges as a significant predictor in the Motivational Self system model in various learning contexts (e.g. Csizér \& Lukács, 2010; Kormos et al., 2011; Papi, 2010; Taguchi et al., 2009).

Instrumentality Prevention scored just less than $.05 \%$ when it comes to predicting and explaining the variance in the reported learning efforts. These findings were also present in Taguchi et al. (2009), who investigated the effects the instrumentally-prevention on students' motivational behaviour toward learning English as a second language.

\section{Conclusion}

This study investigated language learning motivation due to its long term impact on students' success in language learning (Dörnyei, 2005). Based on the findings, three main conclusions were made. Firstly, our findings corroborate the underlying tenet of the L2 Motivational Self system that integrativeness can be relabelled as the Ideal L2 self. Secondly, Ideal L2 is empirically proved to be the most important component of the L2 Motivational Self system model along with Language learning experience; indeed, both of these explain motivated learning behaviour or initial choice. Thirdly, the results did not confirm that instrumentality can be divided into two distinct constructs associated with promotion versus prevention tendencies; this was most likely due to the collective nature of interpersonal relationships in Saudi society.

The limitations of this study include the fact that the participating ESL students were only from one region of Saudi Arabia, and therefore a heterogonous population might show different values of those certain scales, such as contact with L2 community and cultural interest. This type of population might also reveal specific Saudi EFL context factors that are attributed to the environment. Therefore, future research could examine internal and externals factors that boost or diminish the motivational basis of a behavioural intention or an ongoing action among language EFL learners in the Saudi context.

It would also be interesting to explore the use of structural equation modelling to evaluate a motivational model which subsumes Dornier's tripartite model (Ideal L2 self, Ought-to L2 self, and L2 learning experience) as a distinct individual factor or as a secondary factor contributing to variables that act as mediating factors between motivation and success.

\section{References}

Alshehri, A. (2009). Motivation and vision: The relation between the ideal L2 self, imagination and visual style. In Dörnyei, Z., Ushioda, E. (Eds.), Motivation, Language Identity and the L2 Self (pp. 164 -171). Clevedon: Multilingual Matters.

Blommaert, J. (2010). The Sociolinguistics of Globalization. Cambridge: Cambridge University Press.

Chen, J., Warden, C., \& Chang, H. (2005). Motivators that do not motivate: The case of Chinese EFL learners and the influence of Culture on Motivation. TESOL Quarterly, 39(4), 609-633

Coetzee-Van Rooy, S. (2006). Integrativeness: untenable for world Englishes learners? World Englishes, 25 (3), $437-$ 450.

Crooks, G. \& Schmidt, R.W. (1991). Motivation: Re-opening the research agenda. Language Learning, 41, 469-512.

Csizér, K. \& Dörnyei, Z. (2005). The internal structure of language learning motivation and its relationship with language choice and learning effort. Modern Language journal, 89, 19- 36.

Csizér, K. \& Kormos, J. (2008). The relationship of inter-cultural contact and language learning motivation among Hungarian students of English and German. Journal of Multilingual and Multicultural Development, 29, 30-48.

Csizér, K. \& Kormos, J. (2009). Attitudes, selves and motivated learning behaviour: a comparative analysis of structural models for Hungarian secondary and university learners of English. In Dörnyei, Z., Ushioda, E. (Eds.), Motivation, Language Identity and the L2 Self (pp. 98 -119). Clevedon: Multilingual Matters

Csizér, K., \& Lukács, G. (2010). The comparative analysis of motivation, attitudes and selves: The case of English and German in Hungary. System, 38, 1-13.

Dörnyei, Z. (2005). The Psychology of the Language Learner: Individual Differences in Second Language Acquisition. Mahwah, NJ: Lawrence Erlbaum Associates.

Dörnyei, Z. (2007). Research Methods in Applied Linguistics: Quantitative, Qualitative and Mixed Methodologies. Oxford: Oxford University Press

Dörnyei, Z. \& Ushioda, E. (2011). Teaching and researching motivation, $2^{\text {nd }}$ ed. Oxon: Routledge.

Dörnyei, Z. \&Ushioda, E. (2009). Motivation, Language Identity and the L2 Self. Multilingual Matters, Clevedon.

Dörnyei, Z., Csizér, K., \& Németh, N. (2006). Motivation, Language Attitudes and Globalization: A Hungarian Perspective. Clevedon: Multilingual Matters.

Fan, W. (2011). Social influences, school motivation and gender differences: An application of the expectancy-value theory. Educational Psychology Review, 31, 157-175.

Gardner, R. (1985). Social psychology and second language learning: The role of attitudes and motivation. London: Edward Arnold. 
Gardner, R. (2006). The socio-educational model of second language acquisition: a research paradigm. EUROSLA Year book. 6, 237-260.

Gardner, R. \& Lambert, W. (1972). Attitudes and Motivation in Second Language Learning. Rowley, MA: Newbury House.

Higgins, E. (1987). Self-discrepancy: a theory relating self and affect. Psychological Review. 94, 319 - 340.

Heyn, M. (2013). Experiences of male Saudi Arabian international students in the united states. (Unpublished doctoral dissertation). Western Michigan University, Kalamazoo, Michigan

Huang, H., Hsu, C., \& Chen, S. (2015). Identification with social role obligations, possible selves, and L2 motivation in foreign language learning. System, 51, 28-38.

Islam, M., Lamb, M., \& Chambers, G. (2013). The L2 motivational self system and national interest: A Pakistani perspective. System, 41, 231-244.

Kim, T. \& Kim, Y. (2014). EFL students' L2 motivational self-system and self-regulation: Focusing on elementary and junior high school students in Korea. In K. Csizér \& M. Magid (Eds.), The impact of self-concept on language learning (pp. 87107). Bristol, UK: Multilingual Matters.

Kormos, J., Kiddle, T., \& Csizér, K. (2011). Systems of goals, attitudes, and self-related beliefs in second-languagelearning motivation. Applied Linguistics, 32(5), 495- 516

Lamb, M. (2004). Integrative motivation in a globalizing world. System 32, 3-19.

Lamb, M. (2012). A self system perspective on young adolescents' motivation to learn English in urban and rural settings. Language Learning, 1- 27.

Magid, M. \& Chan, L. (2012). Motivating English learners by helping them visualise their Ideal L2 Self: lessons from two motivational programmes, Innovation in Language Learning and Teaching, 6(2), 113-125.

Markus, H. \& Nurius, P. (1986). Possible selves. American Psychologist. 41, 954 - 969.

McClelland, N. (2000). Goal orientations in Japanese college students learning EFL. In: Cornwell, S., Robinson, P. (Eds.), Individual Differences in Foreign Language Learning: Effects of Aptitude, Intelligence, and Motivation (pp. $99-$ 115). Tokyo, Japan: Japanese Association for Language teaching.

McNamara, T. (1997). Theorizing social identity: what do we mean by social identity? Competing frameworks, competing discourses. TESOL Quarterly, 31(3), 561- 567.

Noels, K. (2003). Learning Spanish as a second language: learners' orientations and perceptions of their teachers' communication style. In: Dörnyei, Z. (Ed.), Attitudes, Orientations, and Motivations in Language Learning (pp. 97136)., Oxford: Blackwell.

Norton, B. (1995). Social identity, investment, and language learning. TESOL Quarterly, 29, 9 -31.

Oxford, R. \& Shearin, J. (1994). Language learning motivation: Expanding the theoretical framework. Modern Language Journal, 78, 12- 28.

Oyserman, D., Bybee, D., \& Terry, K. (2006). Possible selves and academic outcomes: how and when possible selves impel action. Journal of Personality and Social Psychology, 91(1), 188- 204.

Pallant, J. (2007). SPSS survival manual: A step by step guide to data analysis using SPSS. Crows West, New South Wales: McGraw-Hill International.

Papi, M. (2010). The L2 motivational self system, L2 anxiety, and motivated behaviour: a structural equation modelling approach. System, 38, 467-479.

Papi, M. \& Teimouri, Y. (2012). Dynamics of selves and motivation: A cross-sectional study in the EFL context of Iran. International Journal of Applied Linguistics, 22(3), 287-309.

Ryan, S. (2009). Self and identity in L2 motivation in Japan: the ideal L2 self and Japanese learners of English. In Dörnyei, Z., Ushioda, E. (Eds.), Motivation, Language Identity and the L2 Self (pp. 120 -143). Clevedon: Multilingual Matters

Sampson, R. (2012). The language-learning self, self-enhancement activities, and self-perceptual change. Language Teaching Research,16(3), 317-335.

Taguchi, T., Magid, M., \& Papi, M. (2009). The L2 motivational self system amongst Chinese, Japanese, and Iranian learners of English: a comparative study. In: Dörnyei, Z., Ushioda, E. (Eds.), Motivation, Language Identity and the L2 Self (pp. 66 -96). Clevedon: Multilingual Matters

Ushioda, E. (2001). Language learning at university: exploring the role of motivational thinking. In Dörnyei, Z., \& Schmidt, R. (Eds.), Motivation and Second Language Acquisition (pp. 91 -124). Honolulu, HI University of Hawaii Press.

You, C., Dörnyei, Z., \& Csizér, K. (2016), Motivation, Vision, and Gender: A Survey of Learners of English in China. Language Learning, 66, 94-123. 